\title{
The numerical simulation of the influence of orientational vibratory stress relief to aluminium alloy 7075-T651 fatigue life
}

\author{
Jing Song ${ }^{1,2, a}$, YiduZhang ${ }^{1,2, b}$, KeSun $^{3, c}$ \\ ${ }^{1}$ State Key Laboratory of Virtual Reality Technology and Systems, Beihang University, Beijing \\ 100191, China \\ ${ }^{2}$ School of Mechanical Engineering and Automation, Beihang University, Beijing 100191, China \\ ${ }^{3}$ Beijing Xinli Machinery Co., Ltd \\ a songjing@buaa.edu.cn, bydzhang@buaa.edu.cn, ${ }^{\circ} 630038480 @ q q . c o m$
}

Keywords:Orientational VSR,7075-T651,Residual stress, Fatigue limit.

\begin{abstract}
For the application situation of traditional vibratory stress relief (VSR) method, technology of orientational VSR was proposed, that is the residual stress distributions of workpiece is simulated by use of finite element method, and then determine the part of workpiece need to reduce residual stress, select the appropriate modal according to the geometry of workpiece and vibrated for residual stress relief. Firstly, the modal analysis was carried out on aluminum alloy 7075-T651 specimen by using finite element method, determine middle section of specimen for VSR, and choose the first order bending vibration mode for vibration mode. The simulation of dynamic stress for specimen was carried out by using transient dynamic analysis method. It is concluded that a linear relationship between the dynamic stress in the direction of $Z$ axis (axial direction of specimen) and amplitude. Secondly, we assigned initial stress in the middle section along the $Z$ axis (axial direction of specimen) of the specimen, the finite element model that contained initial stress for VSR simulation was established, VSR simulated by using transient dynamic analysis method. It is concluded that a quadratic relationship between surface residual stress of the specimen and amplitude. Finally, the fatigue simulation was carried out by using FE-safe software. It is concluded that fatigue strength increased with amplitude, but the phenomenon "much vibration" appeared when amplitude continues to increase that led to decrease of fatigue strength and a quadratic relationship between fatigue limits and amplitude.
\end{abstract}

\section{Introduction}

With the rapid development of modern industry, demands of fatigue life for aluminum alloy are increasing higher and higher.Duringtheproduction and processing of aluminum alloy, the residual stress iscreated inside the material due to various processing variables such as external force and heat.The imbalanced distribution of residual stress is a major cause for the deformation and cracking of aluminum components, greatly affecting the stability of their dimensional accuracy. Besides, the distribution of residual stress also plays a significant role on the fatigue life of aluminum components. Therefore, the homogenized residual stress measures must be taken in the production of aluminum alloy components.

Vibratory Stress Relief (VSR) is a green and efficient aging technology. It prompted the workpiece vibrated under periodic external force, produces micro plastic deformation on componentand makes residual stress relief that led to stable component size. Compared with the traditional natural stressrelief (NSR) and thermal stress relief(TSR), VSR technology hasadvantages of short production cycle, ease of implementation in manufacturing process, low investment cost and so on[1], besides, VSR have high social and economic benefits, also. VSR as an important supplement for NSR and TSR has been widely used in the world [2, 3].

However, researchers have been perplexed by the relationship between VSR load bearing and fatigueprocesses of component.Many researchers have studied the relationship between VSR and fatigue life of components. Song Tian Min [4] studied the influence of VSR on fatigue life of welded components, concluded that VSR can improve its fatigue life.Balasingh [5], Wozney and 
Crawmer [6] believed that fatigue damage due to the VSR treatment could not be neglected but no detailed experimental data were presented to support their view. Sonsino [7] reported that VSR decreases fatigue life of components significantly. Jesensky [8] found no damage in fatigue life ofcomponents due to VSR. Munsi [9], Sun Fenghua and Fang Dexin [10]found higher fatigue life in vibrated specimens. Lu Yaping and He Wen [11] analyzed dislocation and dislocation pileup group stress field using the method of micromechanics, reaching the conclusion that VSR can increase the fatigue life of the specimen.Most of the above investigations were conducted mainly targeting steel, cast iron and welded component, but the researches on aluminum alloy are much less. In view of the traditional VSR application, technology of orientational VSR was proposed, that is the residual stress distributions of workpiece is simulated by use of finite element method, and then determine the part of workpiece need to reduce residual stress, select the appropriate modal according to the geometry of workpiece and vibrated for residual stress relief.The material for the research is aluminum alloy 7075-T651, use ANSYS software to finite element simulation.Determine the position that orientational vibratory stress relief is middle section of specimen by modal analysis. The specimen was assigned initial stress in the middle section of specimen and conducted VSR simulation, the residual stress changed before and after VSR under the condition of first order frequency and various amplitude were studied. On the basis of above, fatigue lives of specimens were studied by fatigue simulation.

\section{7075-T651 aluminum alloy specimen}

7075-T651 is Al-Zn-Mg-Cu series aluminum alloy, it has some excellent performances such us high specific strength and stiffness, great corrosion resistance, high toughness, it can be used in aircraft structures and other high strength structures [12,13,14]. Its composition and mechanical properties are shown in Table 1 and Table 2.Fig. 1 is a schematic illustration of the fatigue specimen, which is designed according to China national standard GB/T 3075-2008 [15], its length is 190mm, and the middle section of specimen is $10 \mathrm{~mm} \times 10 \mathrm{~mm} \times 5 \mathrm{~mm}$.

Table 1 Alloying elements and their concentrations of aluminum alloy 7075-T651 (\%)

\begin{tabular}{cccccccccc}
\hline Elements & $\mathrm{Si}$ & $\mathrm{Fe}$ & $\mathrm{Cu}$ & $\mathrm{Mn}$ & $\mathrm{Mg}$ & $\mathrm{Cr}$ & $\mathrm{Ni}$ & $\mathrm{Zn}$ & $\mathrm{Ti}$ \\
\hline Weight & 0.40 & 0.50 & $1.2 \sim$ & 0.30 & $2.1 \sim$ & $0.18 \sim$ & 0.05 & $5.1 \sim$ & 0.20 \\
Percentage & & & 2.0 & & 2.9 & 0.28 & & 6.1 & \\
\hline
\end{tabular}

Table 2The mechanical properties of aluminum alloy 7075-T651

\begin{tabular}{ccccc}
\hline $\begin{array}{c}\text { Elastic modulus } \\
\mathrm{E} / \mathrm{GPa}\end{array}$ & $\begin{array}{c}\text { Yield strength } \\
\sigma_{\mathrm{s}} / \mathrm{MPa}\end{array}$ & $\begin{array}{c}\text { Tensile strength } \\
\sigma_{\mathrm{b}} / \mathrm{MPa}\end{array}$ & $\begin{array}{c}\text { Density } \\
\rho\left(\mathrm{g} / \mathrm{mm}^{-3}\right)\end{array}$ & $\begin{array}{c}\text { Elongation } \\
\delta / \%\end{array}$ \\
\hline 71.7 & 513 & 578 & 2.81 & 9 \\
\hline
\end{tabular}

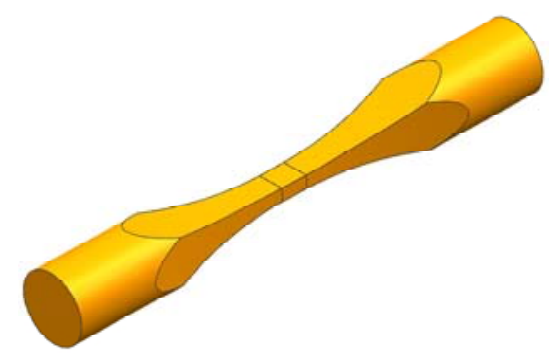

Fig. 1 The fatigue specimen of aluminum alloy 7075-T651 


\section{Finite element simulation}

\subsection{Fatigue specimen modal analysis}

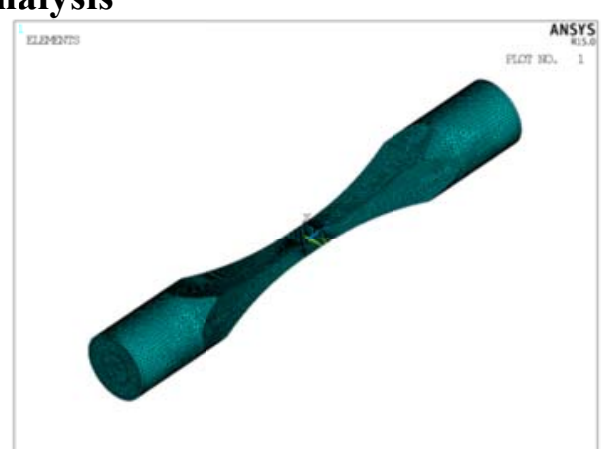

Fig.2 The finite element model of aluminum alloy 7075-T651 specimen

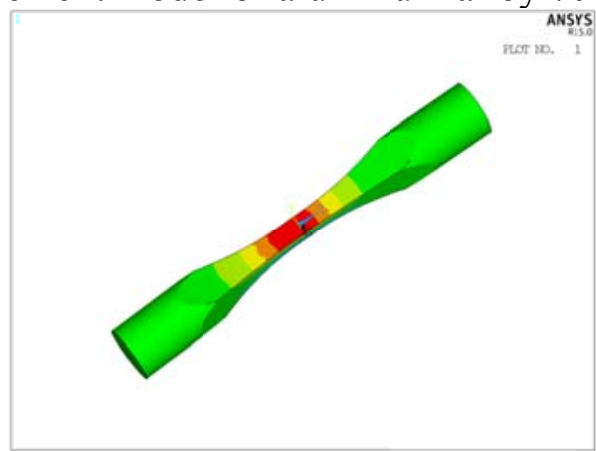

Fig.3 The first order vibration type of aluminum alloy 7075-T651 specimen

The modal analysis used to determine vibration characteristics of the structure, namely determine natural frequencies and vibration type of the structure, they are the important design parameters in structure that bearing dynamic loads. Determine theposition of specimen need to reduce residual stress by modal analysis method, and selected vibration type match to the position that need to residual stress relief according to the theory of orientational vibratory stress relief. The middle section of the specimen was the position that need to residual stress relief in this paper. Fig. 2 is finite element model of aluminum alloy 7075-T651 specimen, use solid185 solid element to grid model, the element size is $0.5 \mathrm{~mm}$ in middle section and else is $1 \mathrm{~mm}$ of the specimen, the total of the element for finite element model is 386729. The first order resonance frequency of fatigue specimen is $109.32 \mathrm{~Hz}$ by FEM modal analysis on the condition of constrained all DOF at one end of specimen and free to the other end. The first order modal of specimen corresponding to the vibration type is bending, and the position that produced maximum dynamic stress was in the middle section of specimen (as can be seen in Fig. 3, the red part is maximum dynamic stress location).

\subsection{Dynamic stress simulation of specimen}

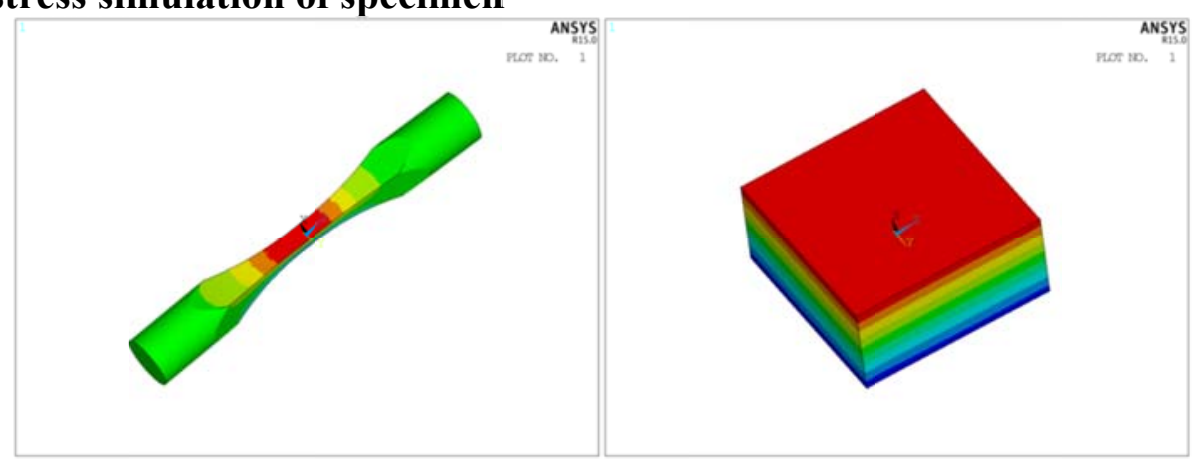

Fig.4 The dynamic stress distribution of specimen when VSR

The dynamic stress depends on amplitude under the condition of certain geometry, vibration mode and vibration frequency, the bigger of the amplitude value, the bigger of the dynamic stress 
value.Because of $\mathrm{Z}$ direction (axial direction of specimen) dynamic stress was biggest and $\mathrm{X} 、 \mathrm{Y}$ direction smaller when vibrated, so studied $Z$ direction dynamic stress only. One end of specimen was constrained all DOF except $X$ axis and free to the other end, dynamic stress were simulated at first order frequency $109.32 \mathrm{~Hz}$ of specimen and various amplitudes in $\mathrm{X}$ direction according to results of modal analysis. The result of whole and middle section of specimen dynamic stress in $\mathrm{Z}$ direction has been shown in Fig. 4 (The red part was the position of biggest dynamic stress). The results of various amplitudes corresponding to dynamic stress values have been shown in Table 3 . Table 3 Various amplitudes corresponding to dynamic stress values

\begin{tabular}{c|ccccccc}
\hline Amplitude $/ \mathrm{mm}$ & 0 & 0.2 & 0.4 & 0.6 & 0.8 & 1.0 & 1.2 \\
\hline Dynamic stress/MPa & 0 & 26.2 & 52.5 & 78.7 & 105 & 131 & 168 \\
\hline
\end{tabular}

According to Table 3, fitting out the curve in Fig. 5 by using least square method, it is can be concluded that a linear relationship between amplitude and dynamic stress in $\mathrm{Z}$ direction, as shown in equation (1):

$\sigma_{\mathrm{d}}=136.8 \mathrm{~A}-1.9$

Where $\sigma_{\mathrm{d}}$ is dynamic stress in $\mathrm{Z}$ direction, unit: $\mathrm{MPa}$. A is amplitude value, unit: $\mathrm{mm}$.

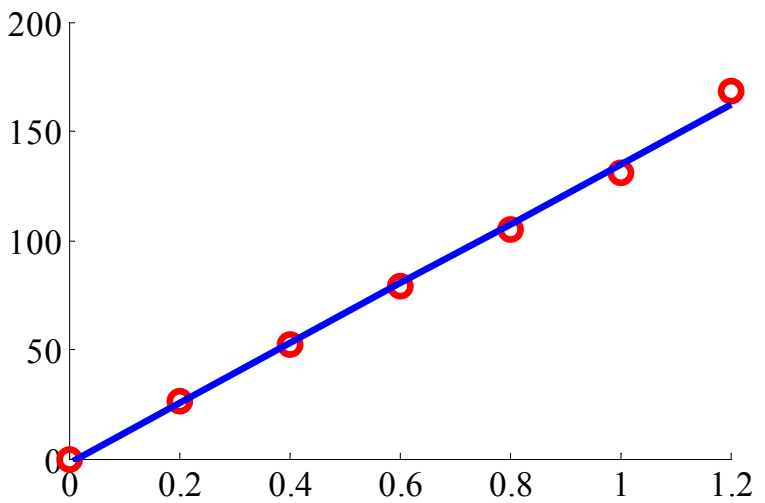

Fig. 5 The amplitude-dynamic curve

\subsection{VSR simulation of specimen}

The position that orientational vibratory stress relief was the middle section of specimen, it was divided to 10 layers. The element shape was hexahedron, its length was $0.5 \mathrm{~mm}$. We assigned residual stress for each layer according to the principle of force and torque balance. Because of residual stress in $\mathrm{Z}$ direction changed largest for the first order bending vibration type, in $\mathrm{X}, \mathrm{Y}$ direction changed smaller, so assigned residual stress in $\mathrm{Z}$ direction for each layer, and assigned residual stress changed along with thickness direction, the residual stress value was assigned as 0 on rest of specimen.It is assumed that initial residual stress distribution along with thickness direction shown in Fig. 6 according to the literature [16], then build up the finite element model that contains initial residual stress has been shown in Fig. 7. On the basis of above, VSR simulated by using transient dynamic analysis method, the residual stress dropped after VSR, residual stress distribution in $\mathrm{Z}$ direction after VSR shown in Fig. 8. The surface residual stress in middle section of specimen corresponding to various amplitudes has been shown in Table 4.

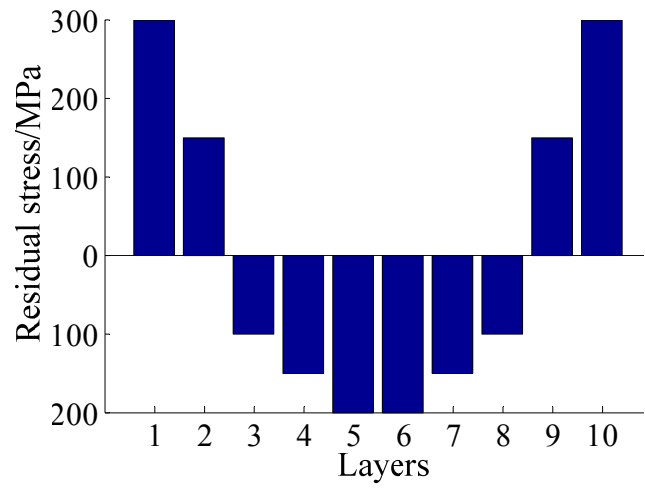

Fig. 6 The initial residual stress distribution along with thickness direction 


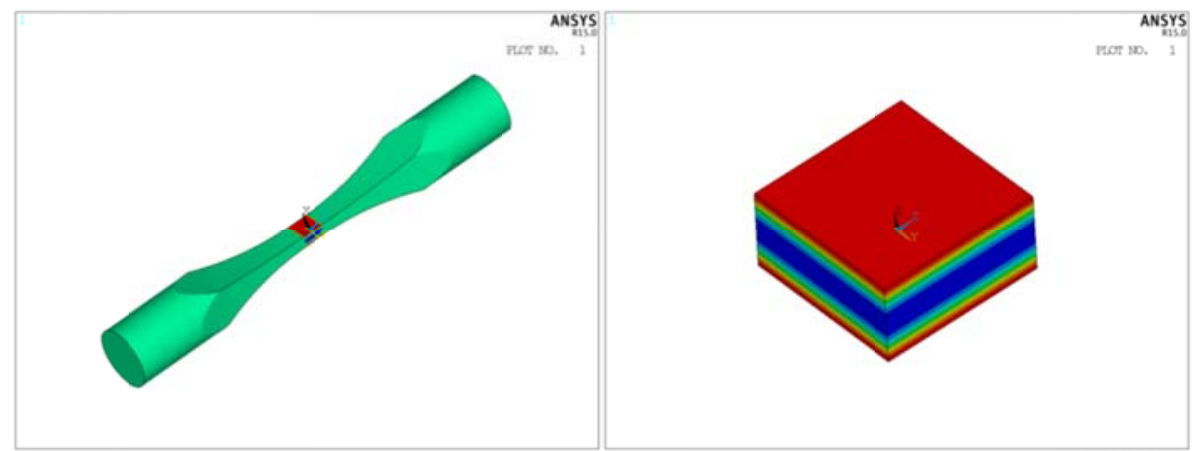

Fig. 7 The finite element model that contains initial residual stress

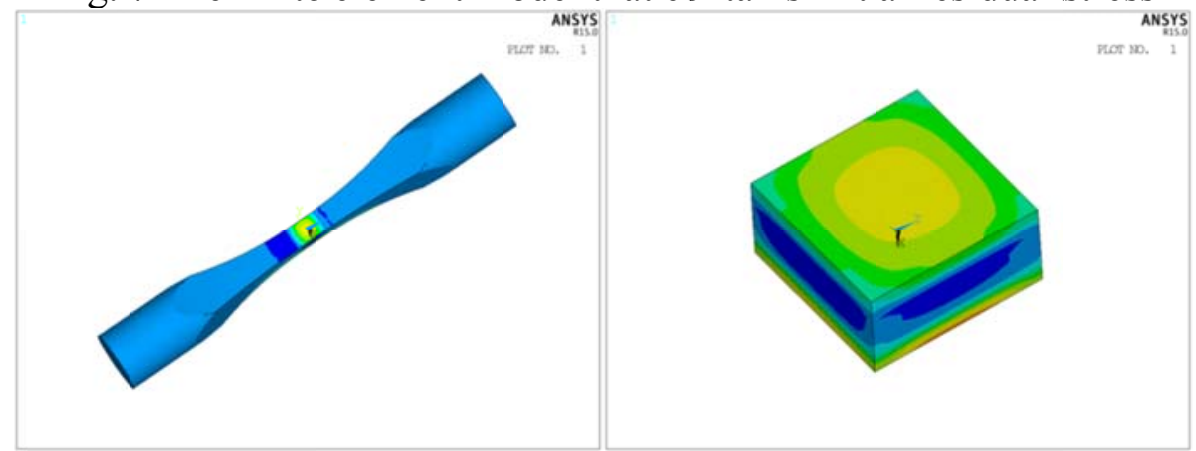

Fig. 8 The residual stress distribution in Z direction after V'SR

Table 4The surface residual stress in middle section of specimen corresponding to various amplitudes

\begin{tabular}{c|ccccccc}
\hline Amplitude $/ \mathrm{mm}$ & 0 & 0.2 & 0.4 & 0.6 & 0.8 & 1.0 & 1.2 \\
\hline $\begin{array}{c}\text { Surface } \\
\text { residualstress/MPa }\end{array}$ & 23.2 & 232 & 204 & 165 & 114 & 122 & 202 \\
\hline
\end{tabular}

According to Table 4, fitting out the curve in Fig. 9 by using least square method, it can be concluded that a quadratic relationship between amplitude and surface residual stress in middle section of specimen, as shown in equation (2):

$$
\sigma_{\mathrm{r}}=266.7 \mathrm{~A}^{2}-427.9 \mathrm{~A}+309.3
$$

Where $\sigma_{\mathrm{r}}$ is residual stress in $\mathrm{Z}$ direction, unit: $\mathrm{MPa}$. A is amplitude value, unit: $\mathrm{mm}$.

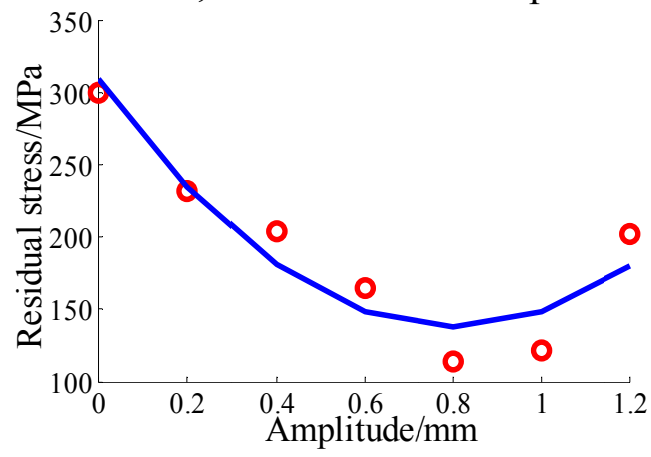

Fig. 9 The curve of amplitude and surface residual stress in middle section of specimen

It can be concluded that the surface residual stress in $\mathrm{Z}$ directiondecreased as amplitude increase, when amplitude reached to $0.8 \mathrm{~mm}$, the surface residual stress was minimum $114 \mathrm{MPa}$ in middle section, the amplitude continued to increase, residual stress can be rose again.

\subsection{Fatigue simulation of specimen}

The FE-safe software was adopted to fatigue simulation of specimen. FE-safe was developed by Safe Technology Company, and then acquired by Dassault Systems. A large number of materials and structures were test in the software development process. FE-safe is widely used in aerospace, automobile, shipbuilding industry, it is an excellent software for fatigue simulation.

On the basis of VSR, import result files to FE-safe after VSR from ANSYS, the fatigue simulation was conducted at stress ratio of -1 corresponding to $10^{7}$ cycles, material was set to 7075-T651 aluminum alloy, surface roughness was set to $0.25<\mathrm{Ra} \leq 0.6 \mu \mathrm{m}$. 
FE-safe will pop-up a result dialog box automatically when FE-safe analysis finished, and generate a suffix called .rst files, import the .rst files to ANSYS, the position of fatigue can be viewed, as shown in Fig. 10.

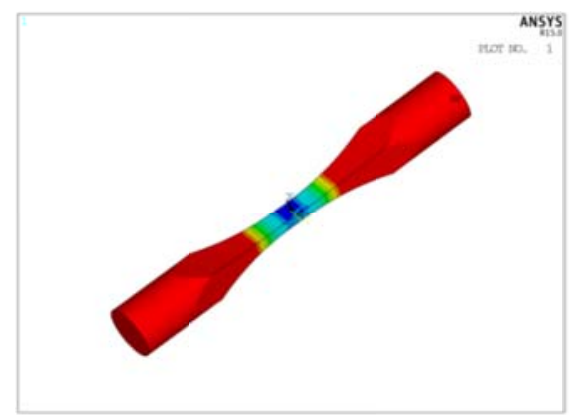

Fig. 10 The position of fatigue on specimen
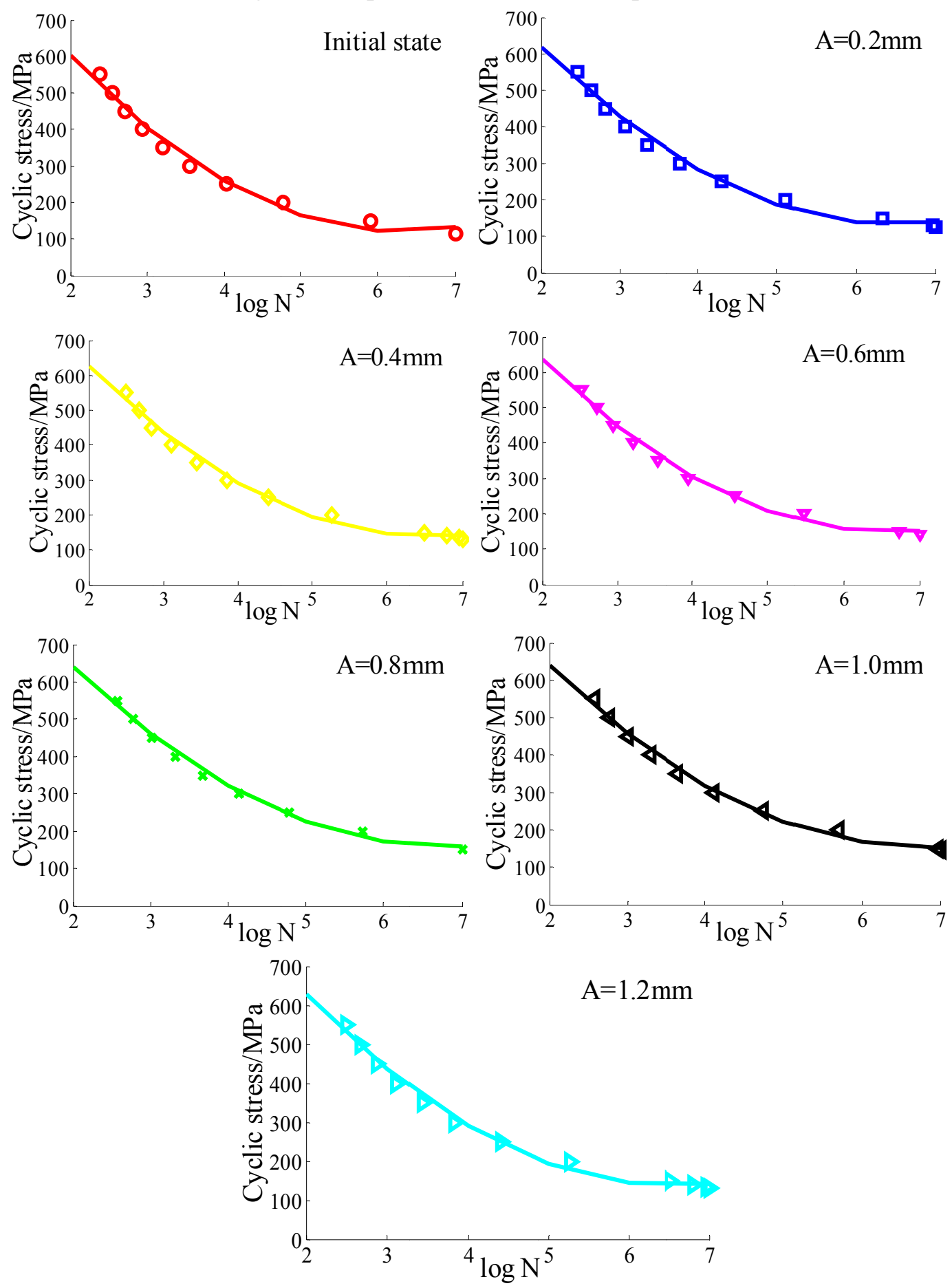

Fig. 11 Various amplitudes S-N curves 
Table 5The fatigue limits in the state of various amplitudes

\begin{tabular}{c|ccccccc}
\hline Amplitude $/ \mathrm{mm}$ & 0 & 0.2 & 0.4 & 0.6 & 0.8 & 1.0 & 1.2 \\
\hline Fatigue limit/MPa & 115 & 125 & 130 & 140 & 150 & 145 & 130 \\
\hline
\end{tabular}

Fig. 11 has been shown S-N curves that the results of fatigue simulation in initial and various amplitudes state. The fatigue limits have been shown in Table 5.

According to Table 5, fitting out the curve in Fig. 12 by using least square method, it can be concluded that a quadratic relationship between amplitude and fatigue limit, as shown in equation (3):

$\mathrm{S}_{-1}=-52 \mathrm{~A}^{2}+81.3 \mathrm{~A}+111.9(3)$

Where $\mathrm{S}_{-1}$ is fatigue limit, unit: MPa. $\mathrm{A}$ is amplitude value, unit: $\mathrm{mm}$.

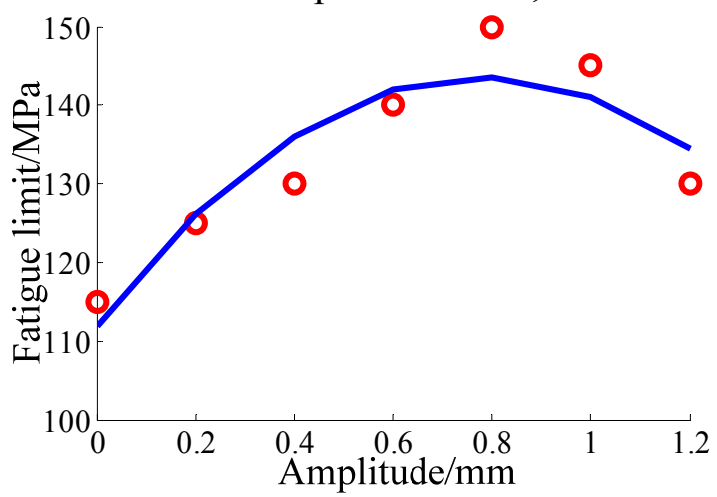

Fig. 12 The curve of amplitude and fatigue limit

With the increase of amplitude, the fatigue strength of 7075-T651 specimen also increased according to fatigue simulation. Fatigue strength reached maximum when amplitude was $0.8 \mathrm{~mm}$, and fatigue limit increased from $115 \mathrm{MPa}$ to $150 \mathrm{MPa}$. The fatigue strength and fatigue limit can be decreased when continue to increase the amplitude.

\section{Conclusion}

1. A linear relationship between amplitude and dynamic stress in $Z$ direction (axial direction of specimen) for 7075-T651 aluminum alloy, with the increase of amplitude, dynamic stress in $Z$ direction (axial direction of specimen) also increased.

2. A quadratic relationship between amplitude and surface residual stress in $Z$ direction (axial direction of specimen) of specimen. The surface residual stress in $Z$ direction (axial direction of specimen) was minimum $114 \mathrm{MPa}$ when amplitude was $0.8 \mathrm{~mm}$. The residual stress can be rose again when amplitude continued to increase.

3. On the basis of VSR, fatigue simulation was conducted. A quadratic relationship between amplitude and fatigue limit. VSR can improve fatigue life of aluminum alloy 7075-T651 in a certain range, and fatigue limit increased from $115 \mathrm{MPa}$ to $150 \mathrm{MPa}$. The phenomenon of "much vibrated" can be occurred when continue to increase amplitude, which led to fatigue strength and limit dropped.

\section{References}

[1]. Y. Zhang. The technology of high efficiency, energy saving and environment friendly in the 21st century. China Mechanical Engineering.Vol.13(2002) No. 19, p. 26-28.

[2]. R. Dawson, D. G. Moffat. Vibratory Stress Relief- - A Fundamental Study of its Effectiveness.Journal of Engineering Material and Technology.Vol.102(1980) No. 2, p. 169-176.

[3]. Y. Y. Gao, L. C. Lin. Review of Vibratory Stress Relief. Journal of Xiangtan Normal University, Vol. 15(1994) No. 6, p. 23-26.

[4]. T. M. Song. Effect of Vibration Time-effect on Fatigue Life of Welds and Its Mechanism. Acta 
Scientiarum Naturalium Universitatis Jilinensis,(1997) No. 2, p. 55-58.

[5]. Balasingh, C, Seshadri, M. R, Srinivasan, M. N and Ramaseshan, S. (1983) Vibrational Stress-Relief of Cast Iron Castings. Indian Foundry Journal. Vol.29(1980) No. 11, p. 129-136.

[6]. Wozney, G. P and Crawmer, G.R. An investigation of vibration stress relief in steel. Welding Research Supplement. Vol.47(1980) No. 9, p. 411-419.

[7].Sonsino, S. M; Muller, F; deBack, J and Gresnigt, A.M. Influence of stress relieving by vibration on the fatigue behaviour of welded joints in comparison to post-weld heat treatment. Fatigue and Fracture of Engineering Materials and Structures. Vol.19(1996) No. 6, p. 703-708.

[8].Jesensky, M. Vibratory lowering of residual stresses in weldments. Proceedings of IIWConference. Sofia, 1987, July, p.153-160.

[9].Munsi, A S M Y, A J Waddell and C A Walker. The Influence of Vibratory Treatment on the Fatigue Life of Welds. A Comparison with Thermal Stress Relief. Vol. 37 (2001) No. 4, p. 141-149.

[10]. F. H. Sun, D. X. Fang. Tests of residual stress on welded structures under vibratory stress relief, Journal of Dalian University of Technology. Vol.34(1994) No. 4, p. 390-393.

[11]. Y. P. Lu, Z, Y, Ma, Q, S, Jia, R, R, Gu. The mechanism research of VSR. Mechanical Science and Technology. Vol.20(2001) No. 4, p. 587-589.

[12]. Xue Y, McDwell D L, Horstemeyer M F, et al. Microstructure-based multistage fatigue modeling of aluminum alloy 7075-T651. Engineering Fracture Mechanics. Vol.74 (2007) No. 17, p. 2810-2823.

[13]. Campbell C E, Bendersky L A, Boettinger W J, et al. Microstructural characterization of Al-7075-T651 chips and workpieces produced by high-speed machining. Materials Science and Engineering A. Vol.430 (2006) No. 1, p. 15-26.

[14]. Y. S. He. A study on Friction-Stir Welds of Thick 7075 Aluminum Plate. Journal of Zhuzhou Institute of Technology. Vol.20 (2006) No. 2, p. 56-58.

[15]. The Chinese national standard GB/T 3075-2008, Metallic materials, the method of axial force control for fatigue test.

[16]. Q. C. Wang, Y, L, Ke, Q, F, Zhang. Evaluation of Residual Stress Depth Profiling in 7075 Aluminum Alloy Plates. Acta Aeronautica ET Astronautica Sinica. Vol.24 (2003) No. 4, p. 336-338. 